J. Lake Sci. (湖泊科学), 2006, 18(6):670-676

http:// www. jlakes. org. E-mail: jlakes@ niglas. ac.cn

(c) 2006 by Journal of Lake Sciences

\title{
长江安庆江段鱼类调查及物种多样性初步研究
}

张敏莹, 徐东坡, 刘凯, 施炜纲 ${ }^{* *}$

(中国水产科学研究院淡水渔业研究中心, 内陆渔业生态环境和资源重点开放实验室,无锡 214081)

摘 要: 对 $1990-2004$ 年长江安庆江段鱼类及物种多样性进行了调查研究. 该江段共有鱼类 46 种, 分别隶属于 9 目 14 科. 按迁徙习性可分为江湖半洄游性鱼类、洄游性鱼类、河口鱼类和定居性鱼类 4 大类型. 小型定居性鱼类占优势, 群落优 势种为黄颡鱼、鲫、鲶、鲤. 多样性特征值年间平均指标为: Margalef 指数 $(R) 1.54$, Wilhm 改进指数 $\left(H^{\prime \prime}\right) 2.14$, McNaughton 指数 $(D w) 0.44$, Pielou 指数 $\left(J^{\prime}\right) 0.75$. 经济鱼类趋于小型化, 四大家鱼资源不容乐观. 必须从根本上降低对长江的捕捞 压力.

关键词: 长江安庆江段;鱼类调查;物种多样性

\section{Ichthyologic survey and primary studies on diversity of fishery species in Anqing section of the Yangtze River}

ZHANG Minying, XU Dongpo, LIU Kai \& SHI Weigang**

( Key Open Laboratory of Ecological Environment and Resources of Inland Fisheries, Freshwater Fisheries Research Center of the Chinese Academy of Fishery Sciences. Wuxi 214081, P. R. China)

\begin{abstract}
Ichthyologic survey and primary studies on diversity of fishery species in Anqing section of the Yangtze River were carried out during 1990 - 2004. Fishes of 9 orders, 14 families and 46 species were collected in this area. There were four ecological types. They were semi-migrated fishes between the Yangtze River and lakes, migrated fishes between the Yangtze River and the sea, estuarine fishes and resident fishes. Most of the fishes were smallsized and resident. Dominant species were yellow catfish, crucian, catfish and common carp. The diversity indexes from 1990 to 2004 were analysed that Margalef 's index was 1.54, Wilhm's index 2.14, McNaughton's index 0.44 and Pielou's index 0.75. Economical fishes had a trend to be small and the rescoures status of the four major Chinese carp were worring. Intensity of fishing must be reduced in the Yangtze River.
\end{abstract}

Keywords : Anqing section of the Yangtze River; ichthyologic survey ; diversity of fishery species

安庆市 $\left(115^{\circ} 16^{\prime}-117^{\circ} 44^{\prime} \mathrm{E}, 29^{\circ} 47^{\prime}-31^{\circ} 17^{\prime} \mathrm{N}\right)$ 位于长江下游北岸, 境内沿江地区湖泊、河流众多. 长江 安庆段长约 $243 \mathrm{~km}$,迂回曲折,多沙洲, 渔业资源丰富, 是我国著名的产鱼区之一. 该江段紧邻著名的铜陵白 暨豚保护区,长江中约 $50 \%$ 的淡水豚栖息生活在此保护区 ${ }^{[1]}$. 鱼类是豚类的主要食物来源,对白暨豚和长 江江豚实行就地保护实质上是对该江段的鱼类资源进行强化管理 ${ }^{[2]}$. 近年来, 湖泊渔业资源的衰退引起了 人们极大的关注和重视, “重建江湖联系, 恢复长江生命活力” 的呼声越来越大. 2004 年 10 月 29 日, 安徽省 安庆市农业委员会渔业局与世界自然基金会签署了合作框架协议,标志着安庆湖群开始实践通江理念. 随 后, 对安庆湖群的水鸟、植被、底栖动物和鱼类的调查研究也陆续展开. 对长江安庆江段渔业资源的最新研 究报道见于 20 世纪 90 年代初 ${ }^{[3]}$, 近年对该江段渔业资源的研究尚未见报道. 本文依据 $1990-2004$ 年长江 下游渔业资源动态监测数据, 从群落结构及生物多样性变化等方面对该江段鱼类群落进行描述, 以期为该

* 农业部海洋与河口渔业重点开放实验室长江水生生物资源保护与管理小额基金 ( $\mathrm{C}-2005-05)$ 、世界自然基金会 汇丰银行长江项目、无锡市自然科学基金项目 (CK040007) 共同资助. 2005-09-26 收稿;2005-12-14 收修改 稿. 张敏莹,女, 1974 年生, 硕士, 助理研究员; E-mail: zhangmy@ ffrc. cn.

** 通讯作者:施炜纲, 研究员; E-mail: shiwg@ffrc. cn. 
江段渔业资源管理、沟通江湖联系和保护豚类资源提供基础数据和理论依据.

\section{1 材料与方法}

\section{1 数据采集方法}

$1990-2004$ 年间在安庆沙漠洲、皖河口各设立 1 个采样点, 以定置张网截捕过往的水生动物. 网宽 50 $\mathrm{m}$, 网高 $3 \mathrm{~m}$, 网目 $2 \mathrm{~cm}$, 张网截拦面积 $150 \mathrm{~m}^{2}$. 张网监测时间为全年 $1-12$ 月, 每月监测 $2 \mathrm{~d}$, 每天放网 $24 \mathrm{~h}$.

\section{2 研究对象}

群落研究以 $2002-2004$ 年所有采样鱼类为研究对象, 生物多样性研究以各年采样鱼类为研究对象.

\section{3 生物多样性统计}

采用 Margalef 指数 ${ }^{[4]} 、$ Wilhm 改进指数 ${ }^{[5]} 、$ McNaughton 指数 ${ }^{[6]}$ 、Pielou 指数 ${ }^{[7]}$ 等多样性特征值对安庆江 段鱼类生物多样性进行描述.

Margalef 指数: $R=(S-1) / \ln \mathrm{N}$ 反映群落物种丰富度

Wilhm 改进指数: $H^{\prime \prime}=-\sum\left(W_{i} / W\right) \ln \left(W_{i} / W\right)$ 基于物种生物量反映群落种类多样性

McNaughton 指数: $D w=\left(W_{1}+W_{2}\right) / W$ 基于物种生物量反映群落物种优势度

Pielou 指数: $J^{\prime}=H / H_{\max }=H / \ln S$ 反映群落均匀度

式中, $S$ 为群落中所有物种的种类数, $N$ 为群落中所有物种的数量, $W$ 为群落中所有物种的生物量, $W_{i}$ 为第 $i$ 个物种的生物量, $W_{1} 、 W_{2}$ 为群落中生物量优势种排序居于第一、二位的物种的生物量.

\section{2 结果与分析}

\section{1 群落组成结构}

$2002-2004$ 年安庆江段 2 个采样点定置张网中出现的鱼类共有 46 种, 分别隶属于 9 目 14 科. 群落结 构中鲤形目占明显优势, 其它各目差别不大 (表 1 ).

\section{表 1 长江安庆江段鱼类群落结构}

Tab. 1 Stucture of fish community in Anqing section of the Yangtze River

\begin{tabular}{|c|c|}
\hline 种类 & 种类 \\
\hline I 鲤形目 Cypriniformes & 29. 鲶 Parasilurus asotus( Linnaeus) \\
\hline $\mathrm{i}$ 鲤科 Cyprinidae & $\mathrm{V}$ 胡子鲶科 Clariidae \\
\hline 1. 鲤 Cyprinus carpio Linnaeus & 30. 革胡子鲶 Clarias leather \\
\hline 2. 鲫 Carassius auratus auratus (Linnaeus) & vi 鮠科 Bagridae \\
\hline 3. 鳙 Aristichthys nobilis (Richardson) & 31. 黄颡鱼 Pelteobaggrus fulvidraco(Richardson) \\
\hline 4. 鲢 Hypophthalmichthys molitrix (Cuvier et Valenciennes) & 32. 江黄颡鱼 Pelteobaggrus vachelli( Richardson) \\
\hline 5. 草鱼 Ctenopharyngodon idellus (Cuvier et Valenciennes) & 33. 光泽黄颡鱼 Pelteobaggrus nitidus (Sauvage et Dabry) \\
\hline 6. 铜鱼 Coreius heterodon (Bleeker) & 34. 岔尾黄颡鱼 Pelteobaggrus eupogon (Boulenger) \\
\hline 7.㽜条 Hemiculter leucisculus (Basilewsky) & 35. 长吻鯔 Leiocassis longirostris Gunther \\
\hline 8. 银色领须鮈 Gnathopogon argentatus (Sauvage et Dabry) & IV 鲱形目 Clupeiformes \\
\hline 9. 趐嘴红鲌 Cu1 ter ilishaeformis (Bleeker) & vii 鲱科 Clupeidae \\
\hline 10. 圆吻鲖 Distoechodon tumirostris Peter & 36. 刀鲚 Coilia macrognathos Bleeker \\
\hline 11. 青鱼 Mylopharyngodon piceus (Richardson) & 37. 短领鲚 Coilia brachygnathus Kreyenberg et Pappenheim \\
\hline 12. 银鲖 Xenocypris argentea Gunther & $\mathrm{V}$ 鲇形目 Perciformes \\
\hline 13. 赤眼鯂 Squaliobarbus curriculus (Richardson) & viil 鮨科 Serranidae \\
\hline 14. 油㽜条 Hemiculter bleekeri Warpachowsky & 38. 大眼鳜 Siniperca kneri Garman \\
\hline 15. 黄尾鲖 Xenocypris davidi Bleeker & 39. 鰦 Siniperca chuatsi (Basilewsky) \\
\hline 16. 逆鱼 Pseudobrama simony (Bleeker) & 40. 长身鳜 Siniperca roulei $\mathrm{Wu}$ \\
\hline 17. 细鳞斜领鲖 Xenosypris microlepis Bleeker & ix 塘鳢科 Eleotridae \\
\hline
\end{tabular}




\begin{tabular}{|c|c|}
\hline 种类 & 种类 \\
\hline 18. 鳊 Parabramis pekinensis (Basilewsky) & 41. 沙鳢Odontobutis obacurus( Temminck et Schlegel) \\
\hline 19. 银飘 Pseudolaubuca sinensis Bleeker & $\mathrm{X}$ 鳢科 Channidae \\
\hline 20. 吻鮈 Rhinogobio typus Bleeker & 42. 乌鳢 Channa argus (Cantor) \\
\hline 21. 蛇鮈 Saurogobio dabryi & VI 鲽形目 Pleuronectiformes \\
\hline 22. 高体鰟鮍 Rhodeus ocellatus & xi 舌鳎科 Cynoglossidae \\
\hline 23. 麦穗鱼 Pseudorasbora parva ( Temminck et Schlegel) & 43. 三线舌鳎 Cynoglossus trigrammus Gunther \\
\hline 24. 棒花鱼 Abbottina rivularis (Basilewsky) & VII 合鳃目 Synbranchiformes \\
\hline 25. 鳡 Elopichthys bambusa & xii 合鳃科 Synbranchidae \\
\hline 26. 黑鯺鰁 Sarcocheilichthys nigripinnis ( Gunther) & 44. 黄鳝 Monopterus albus (Zuiew) \\
\hline ii 䱊科 Cobitidae & VIII 鲻形目 Mugiliformes \\
\hline 27. 泥䱊 Misgurnus anguillicaudatus & xiii 鲻科 Mugilidae \\
\hline II 鲟形目 Cyprinodontiformes & 45. 鲻鱼 Mugil cephalus \\
\hline iii 青鲟科 Oryziatidae & IX 鳗鲡目 Anguilliformes \\
\hline 28. 青鳉Oryzias laptipes (Temminck et Schlegel) & xiiii 鳗鲡科 Anguillidae \\
\hline III 鲶目 Siluriformes & 46. 鳗鲡 Anguilla japonica Temminck \\
\hline iv 鲶科 Siluridae & \\
\hline
\end{tabular}

\section{2 群落生态类型}

从迁徙习性、食性两个方面对该群落进行分类. 按迁徙习性可分为 4 大类型: (1) 江湖半洄游性鱼类, 如青、草、鲢、鳙、鳡等; (2) 洄游性鱼类,如鳗鲡、刀鲚; (3) 河口鱼类,如鲻鱼、舌鳎; (4) 定居性鱼类, 如鲤、 鲫、鲶、短领鲚、鰟鮍等. 按食性可分为 6 个类型: (1) 以浮游藻类为主食的有鲢、银鲖; (2) 以浮游动物为主 食的有鳙、刀鲚、短领鲚、吻鮈等; (3) 以底栖无脊椎动物为主食的有蛇鮈、铜鱼、青鱼、黄鳝、黄颡鱼等; (4) 以水生高等植物和腐屑为主食的有草鱼、鳊鱼、黄尾鲖等; (5) 以鱼为主食的有翅嘴红鲌、鳡、鲶、乌鳢、长吻 鮸、鮵类等; (6) 广食性种类有鲤、鲫、泥鱾、㽜条等.

\section{3 优势种组成及重量分布}

将采样鱼类按数量和生物量汇总. 以渔获数量计, 黄颡鱼、鲫、餐条排在优势种的前 3 位, 其次是鲖、鲶、 鮈、鲤; 以渔获生物量计, 前 7 位优势种依次为鲢、鲤、鲶、黄颡鱼、鲫、草、鳙, 其中鲢、鳙、草鱼所占比例高达 $28.95 \%$. 不论是以渔获数量或是以渔获生物量计, 在前 7 位优势种排序中, 黄颡鱼、鲫、鲶、鲤都占有较大的 比例, 是该江段鱼类群落的优势种 (表 2).

表 2 长江安庆江段前 7 位优势种组成 *

Tab. 2 Composition of top seven species in Anqing section of the Yangtze River

\begin{tabular}{cccc}
\hline \multicolumn{2}{c}{ 以渔获数量计 } & \multicolumn{2}{c}{ 以渔获生物量计 } \\
\hline 种类 & 所占比例 $(\%)$ & 种类 & 所占比例 $(\%)$ \\
\hline 黄颡鱼 & 27.36 & 鲢 & 19.47 \\
鲫 & 12.92 & 鲤 & 16.52 \\
㛑条 & 10.12 & 鲶 & 16.39 \\
鲖 & 9.90 & 黄颡鱼 & 9.09 \\
鲶 & 7.55 & 鲫 & 7.58 \\
鮈 & 6.69 & 草鱼 & 5.54 \\
鲤 & 6.17 & 鳙 & 3.94 \\
合计 & 80.72 & 合计 & 78.54 \\
\hline
\end{tabular}

* 黄颖鱼包括江黄颞鱼、黄颡鱼、岔尾黄颡鱼、光泽黄颡鱼等; 㽜条包括油㽜条; 鲖包括银鲖、黄尾鲖等; 鮈包括蛇鮈、吻鮈等. 
计算各个种的单位均重, 统计重量分布区间: 单位均重小于 $50 \mathrm{~g}$ 的有 21 种, 其种类数占群落种类总数 的 $45.65 \%$, 其中单位均重小于 $20 \mathrm{~g}$ 的种类数 (9 种) 占群落种类总数的 $19.56 \%$; 单位均重大于 $500 \mathrm{~g}$ 的种 类数占群落种类总数的 $2.17 \%$; 单位均重在 $50-500 \mathrm{~g}$ 的种类数占群落种类总数的 $52.18 \%$.

\section{4 群落生物多样性}

$1990-2004$ 年长江安庆段鱼类群落生物多样性特征值平均指标为: Margalef 指数 $(R)$ 1.54、Wilhm 改 进指数 $\left(H^{\prime \prime}\right) 2.14 、$ McNaughton 指数 $(D w) 0.44$; Pielou 指数 $\left(J^{\prime}\right) 0.75$ (表 3). 刘凯等 ${ }^{[8]}$ 报道崇明北滩鱼类群 落物种丰富度指数均值为 0.84 , Wilhm 改进指数 $(H d)$ 为 $1.51, \mathrm{McNaughton}$ 指数为为 0.67 ,均匀度指数为 0.63 ; 凌去非等 ${ }^{[9]}$ 的研究表明长江天鹅洲故道鱼类群落的 wilhm 改进指数为 4.19 , 均匀度指数为 0.66 . 与 崇明北滩及天鹅洲故道相比, 长江安庆段鱼类群落均匀度较高, 优势度较低, 丰富度、多样性处于中等水平.

对各年物种多样性指数分别与物种丰富度、优势度和物种均匀度进行相关分析, 结果表明物种多样性 与丰富度、均匀度之间均呈显著的正相关关系, 而与优势度之间呈显著的负相关关系, 相关系数依次为 $0.77 、 0.86 、-0.70$. 这和温新利等 ${ }^{[10]}$ 对轮虫物种多样性及李学军等 ${ }^{[11]}$ 对天鹅洲故道和老河故道水生生物 多样性的研究结果类似.

对多样性指数的年间变化趋势进行分析: 研究期内丰富度指数 $R$ 、Wilhm 改进指数 $H^{\prime \prime}$ 变化幅度较大, 在 $1990-1997$ 年两者均呈下降趋势, 自 1998 年始两指数表现出明显的上升趋势, 特别是自 2002 年始, 由 于实行了春季禁渔, 丰富度指数 $R 、$ Wilhm 改进指数 $H^{\prime \prime}$ 都有较大幅度上扬, 这说明春禁对该江段鱼类群落 起到了一定的保护作用,春禁后群落结构趋于复杂; $1990-2004$ 年均匀度指数 $J$ 、优势度数 $D w$ 在窄幅范围 波动, 该江段鱼类群落始终维持着较高的均匀度和较低的优势度 (图 1 ). 应该指出的是, 在丰富度指数 $R$ 、 Wilhm 改进指数 $H^{\prime \prime}$ 上扬的同时, 2002-2004 年均匀度指数 $J$ 有所下滑、优势度数 $D w$ 上升,可能和春禁期大 量放流大规格四大家鱼苗种有关.

表 3 安庆江段鱼类群落多样性特征值

Tab. 3 Characters of biodiversity of fish community in Anqing section

\begin{tabular}{ccccc}
\hline 年份 & $R$ & $H^{\prime \prime}$ & $D w$ & $J^{\prime}$ \\
\hline 1990 & 1.71 & 2.46 & 0.39 & 0.74 \\
1991 & 1.82 & 2.66 & 0.25 & 0.81 \\
1992 & 1.85 & 2.21 & 0.47 & 0.72 \\
1993 & 1.85 & 2.49 & 0.30 & 0.82 \\
1994 & 1.45 & 2.10 & 0.49 & 0.76 \\
1995 & 1.37 & 1.78 & 0.41 & 0.73 \\
1996 & 1.17 & 1.63 & 0.65 & 0.64 \\
1997 & 1.20 & 1.80 & 0.62 & 0.70 \\
1998 & 1.47 & 1.67 & 0.65 & 0.59 \\
1999 & 1.54 & 2.01 & 0.45 & 0.78 \\
2000 & 1.33 & 2.17 & 0.33 & 0.82 \\
2001 & 1.16 & 2.09 & 0.47 & 0.84 \\
2002 & 1.63 & 2.39 & 0.33 & 0.81 \\
2003 & 1.76 & 2.41 & 0.40 & 0.77 \\
2004 & 1.72 & 2.26 & 0.44 & 0.72 \\
均值 & 1.54 & 2.14 & 0.44 & 0.75 \\
\hline
\end{tabular}

\section{3 讨论}

\section{1 关于长江安庆段“重建江湖联系”的背景}

江湖阻隔后带来极为严重的生态后果. 湖泊内鱼类不能进人长江越冬和繁殖, 而长江中的四大家鱼和 其它鱼类的幼鱼不能进人湖泊摄食育肥, 留在湖泊里的四大家鱼等鱼类又因缺乏一定的流速、流量等必需 的生态条件不能繁衍后代, 这样就使江河和湖泊中的鱼类群落都表现出种类减少、资源衰退 ${ }^{[12]}$. 江湖阻隔 


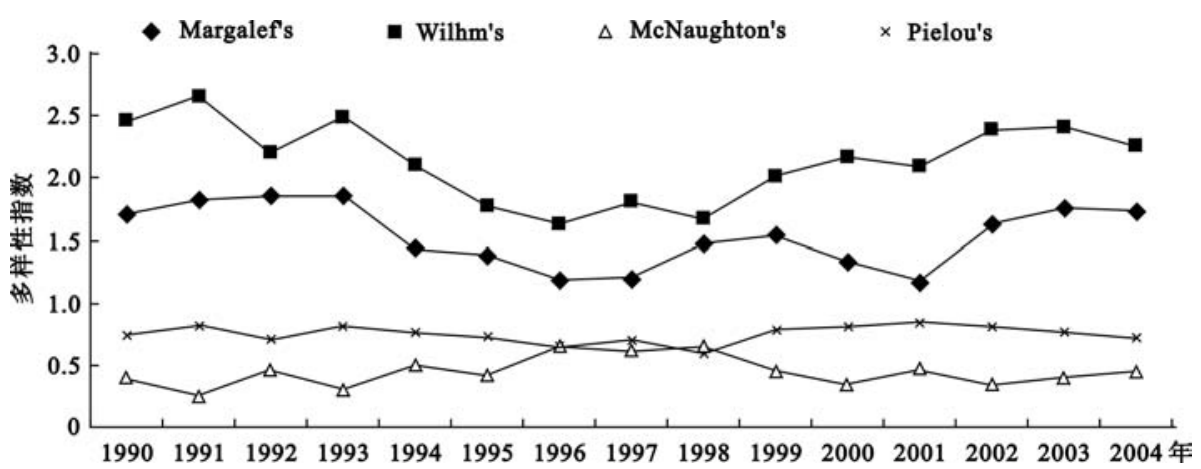

图 1 安庆江段鱼类群落生物多样性指数变动

Fig. 1 Indexes variation of biodiversity of fish community in Anqing section of the Yangtze River

导致的生态后果引起人们极大的关注和重视, 2002 年香港上海汇丰银行设立世界自然基金汇丰银行 ( WWF - HSBC) 专项基金, 资助包括长江项目在内的全球多个自然保护计划. 安庆市境内河湖密布, 江湖水 面为 $1623.7 \mathrm{~km}^{2}$, 占安徽省水面的 $10.3 \%$. 其中湖泊面积 $1147.2 \mathrm{~km}^{2}$, 占全市水面的 $70.6 \%$; 江河水面 $375.8 \mathrm{~km}^{2}$, 占 $23.1 \%$; 水库面积 $85.2 \mathrm{~km}^{2}$, 占 $5.24 \%$. 安庆湖群是长江中下游除鄱阳湖、洞庭湖之外的第三 处面积最大且地理位置极重要的湖泊群. 历史上, 安庆湖群均与长江自然相通, 但是, 自 20 世纪 50 年代以 来, 由于筑堤建闸、围湖造田等原因,这些湖泊中的绝大多数不再与长江自然相通而成为阻隔湖泊 (如华阳 湖群、武昌湖群、白荡湖等). 在考察了 WWF - HSBC 长江项目在武汉市新洲区涨渡湖、石首市天鹅洲、洪湖 等三地基于 “灌江纳苗”重建江湖季节联系的阶段性工作成果基础上,2005 年春季,安庆市农委及有关部门 决定率先在白荡湖实施 “灌江纳苗, 重建江湖联系”, 此举不仅对科学合理利用当地渔业资源、促进当地渔 业经济健康可持续发展具有重要意义,同时也将对保护长江流域湿地资源起到良好的推动作用.

\section{2 采样网具与方法的选定}

因为每种网具都具有选择性, 如果要对某一区域的实际群落组成及结构进行研究,最好采用多种网具 相结合 ${ }^{[13]}$. 张网是一种被动近岸作业网具, 它具有采样成本低、取样方便、采样点可控性好的优点, 因此始 于 1989 年的长江渔业资源动态监测一直采用张网. 必须指出的是, 由于张网只能布置在近岸浅水带, 渔获 中小型鱼类出现的几率相对要高些 ${ }^{[14]}$, 因此采样所得物种数量及组成可能和该江段实际情况存在一定差 异. 胡菊英等 ${ }^{[3]}$ 曾用多种网具采样和市场调查相结合的方法对长江安徽段鱼类进行调查, 结果表明长江安 徽段有鱼类 106 种,其中见于安庆段的为 63 种. 和上述研究结果相比, $1990-2004$ 年张网采样的调查结果 少了 17 个物种, 它们主要是银鱼类 (4 个种)、鱊类 (5 个种) 和鲌亚科鱼类 (4 个种). 除 4 种鲌亚科鱼类外, 银鱼类和鱊类均为小型鱼类, 可见调查结果受张网采样局限性的影响不大, 因此我们的调查结果具有一定 的可靠性、参考性.

\section{3 群落结构及组成}

从生态角度分析, 群落结构发生较大变化: 洄游性、半洄游性鱼类减少, 河口性鱼类出现的频次和定居 性鱼类有增多的趋势. 2002-2005 年 (3-6 月) 刀鲚在渔获重量中所占年均比例仅为 $1.01 \%$,处于极低水 平,鳗鲡在 15 年的监测中只出现 2 尾; 半洄游性四大家鱼减少, 群落中定居性鱼类鲤、鲫、鲶、黄颡鱼占优势 (表 2); 舌鳎在 $1990-2001$ 年的监测中出现 1 尾,2002-2004 年出现 3 次计 3 尾;2004 年 6 月该江段首次 监测到 1 尾鲻鱼. 由于缺乏气象、水文、水质等方面的资料,该江段河口性鱼类 (舌鳎、鲻鱼等)在渔获物中 出现频次发生变化的原因有待于进一步研究.

从群落组成来看, 以黄额鱼、䱗条、鲖、鮈等为主的小型鱼类占优势, 以四大家鱼为主的大型经济鱼类所 占比例明显偏低.于道平等 ${ }^{[15]}$ 的研究表明 2000 年铜陵江段四大家鱼在渔获物中所占比例不足 $10 \% .2002$ - 2004 安庆段的监测表明四大家鱼占渔获物生物量的 $29.97 \%$,明显高于铜陵江段. 但从渔获规格来看,除 
鳙鱼 (均重 $536.82 \mathrm{~g}$ ) 外, 四大家鱼个体明显偏小, 单位均重都在 $200 \mathrm{~g}$ 左右, 即渔获物中四大家鱼多为近年 春禁期放流的大规格苗种. 因此, 安庆段的四大家鱼资源和其它江段 ${ }^{[16]}$ 一样不容乐观.

从渔获物规格来看,鱼类群落表现出明显小型化:一是小型种类逐步代替大型种类,即黄颡鱼、㽜条、 鲖、鮈、鲫等单位均重小于 $50 \mathrm{~g}$ 的小型种类占群落种类总数的 $45.65 \%$, 单位均重大于 $500 \mathrm{~g}$ 的大型种类仅占 $2.17 \%$,介于两者之间的种类数占 $52.18 \%$; 二是捕捞个体小型化, 表现为像草鱼、青鱼、鲢、鲤这样的大型鱼 类,在渔获物中仍只有未成长的小型个体 (均重依次为 $216.87 、 121.58 、 256.11 、 164.97 \mathrm{~g}$ ).

\section{4 优势种的判别标准}

朱金华等 ${ }^{[17]}$ 转引报道了由出现频率高低决定的常见种 (Regula 出现月次大于 9 个月)、季节种 (Seasonals:5-8 月次) 和偶见种 (Occasionals: 1-4 月次) 的优势种标准. 据此标准,对长江安庆段的监测表明, 鱼类群落内常见种、季节种和偶见种分别为 $28,12,6$ 种, 即三者间差别较大, 与渤海鱼类群落相比 ${ }^{[17]}$, 物种 间季节变动节律不明显. 郁尧山等 ${ }^{[18]}$ 认为物种生物量 (或数量) 超过当年总生物量 (或数量) 的 $10 \%$ 的为当 年优势种, 按此标准安庆段优势种为鲢、鲤、鲶 3 种.

作者认为,由出现频率高低决定的优势种标准适用于季节性变化很大的海洋鱼类群落,郁尧山的优势 种标准适用于物种数较少且优势度大的河口鱼类群落 ${ }^{[8]}$, 对于像长江安庆段这样物种数较多、均匀度较大 且季节变动节律不明显的鱼类群落,依物种生物量 (或数量) 所占比例确定优势种较合适; 但这样确定的优 势种仅为鲢、鲤、鲶 3 种, 如将 10\% 的比例标准降低至 7\% 左右, 黄颡鱼、鲫也在优势种之列（表 2 ), 这样界 定的优势种可能更好地与该江段鱼类群落的实际情况吻合.

\section{4 影响该江段鱼类资源的因素及资源保护措施}

航运、挖沙、水域污染、水利工程和捕捞是影响该江段鱼类资源的主要因素.

有关研究表明, 长江下游每小时通过船只 67.4 艘, 是中游的 5 倍 ${ }^{[15]}$. 长江船只大幅度增加, 压缩了鱼 类的活动空间、干扰了鱼类的摄食、繁殖; 肆意挖沙破坏水下生态环境,威胁鱼类生命安全; 长江下游水域不 同程度的污染 ${ }^{[19,20]}$ 及大型水利工程都对鱼类资源造成一定的危害; $1990-2004$ 年安庆段的监测表明渔获 物中 $45.65 \%$ 的种类个体均重不足 $50 \mathrm{~g}$,渔获物明显小型化; 施炜纲等 ${ }^{[21]}$ 的研究表明,2001-2004 年春禁期 间 (4-6月), 安庆段物种多样性指数与河蟹、刀鲚等捕捞证的发放数呈显著负相关. 由此可见,过度捕捞仍 然是影响该江段鱼类资源的最根本原因. 近年来实行的“长江春禁” 以及 “灌江纳苗”等措施对保护长江渔 业资源、恢复长江生命活力起到了一定的积极作用, 但并没有从根本上降低对长江的捕捞压力. 因此, 保护 该江段渔业资源, 除了降低航运及水利工程的危害、限制挖沙、治理水域污染外,要从根本上降低对长江的 捕捞压力: 沿江专业渔民一是要走转产转业之路, 二是应该发展以养殖为主体, 以养代捕, 实现捕捞渔业逐 步退出长江. 长江在我国淡水渔业中的地位是基因库、原种基地和珍稀物种的乐园,而不应是天然渔场.

\section{5 参考文献}

１1］陈佩萤,刘仁俊等. 长江中游 (武汉一一岳阳江段) 豚类的分布、生态、行为和保护. 海洋与湖沼, 1980 , 11( 10$): 73-74$.

[2] 董明利, 于道平, 梁太芹, 王 渊. 建立铜陵淡水豚自然保护区考察研究. 安徽大学学报 (自然科学 版), 2000,24(4) :98-105.

[3] 胡菊英,姚文卿. 长江下游安徽江段的鱼类. 安徽大学学报 (自然科学), 1996,20(1):96-101.

[4] Margalef D R. Information theory in ecology. Gen Syst, 1957, 3:36 - 71.

[5] Wilhm J L. Use of biomass units in Shanno's formula. Ecology, 1968, 49:153 - 156.

[6] McNaughton S L. Diversity and stability. Nature, 1988,333:204 - 205.

[7] Pielou E C. Ecological diversity. New York: John Wiley, 1975:1-165.

[8] 刘 凯, 徐东坡, 张敏莹等. 崇明北滩鱼类群落生物多样性初探. 长江流域资源与环境, 2005,14(4): $416-421$.

［9］凌去非, 李思发. 长江天鹅洲故道鱼类群落种类多样性. 中国水产科学, 1998,5(2):1-5. 
[10] 温新利, 席贻龙, 张 雷等. 青七江芜湖段轮虫群落结构和物种多样性的初步研究. 生物多样性, 2004, 12 ( 4 ) :387 - 395.

[11] 李学军,李思发,杨和荃. 长江天鹅洲故道和老河故道水生生物多样性的比较研究. 生物多样性, 1996, 4 ( 4 ) :211-216.

[12] 王利民,王 丁. 长江流域的渔业与湿地保护. 人民长江, 2004,35(5):37-39.

[13] 凌去非,李思发. 长江天鹅洲故道鱼类群落种类多样性. 中国水产科学, 1998,5(2):1-5.

[14] 施炜纲, 王 博, 王利民. 长江下游水生动物群落生物多样性变动趋势初探. 水生生物学报, 2002,26 (6) :654-661.

[15] 于道平, 董明利, 王 江. 铜陵江段豚类资源与保护措施的研究. 浙江海洋学院学报 (自然科学版), $2002,21(3): 236-241$.

[16] 邱顺林,刘少平, 黄木桂等. 长江中游四大家鱼资源调查. 水生生物学报,2002,26(6):716-718.

[17］朱金华, 杨纪明, 唐启升. 渤海鱼类群落结构特征的研究. 海洋与湖沼, 1996,27(1):6-1.

[18] 郁饶山. 浙江北部岛礁周围海域鱼类优势种及其种间关系的初步研究. 水产学报, 1986,10(2):137 -150 .

[19] 胡庚东,陈家长,尤 洋等. 长江安徽段白顋豚栖息地生态环境的调查及评价. 青海畜牧兽医杂志, 30 (4) : $: 15-17$.

[20] 陈家长,孙正中,篗建宏等. 长江下游重点江段水质污染及对鱼类毒性的影响. 水生生物学报,2002,26 (6),635-640.

[21] 施炜纲,刘 凯, 张敏莹等. 春季禁渔期间长江下游鱼虾蟹类物种多样性变动 (2001-2004 年). 湖泊 科学, 2005,17(2) : 169-175 